\title{
A positive theory of network connectivity
}

\author{
David Levinson, Arthur Huang \\ Department of Civil Engineering, University of Minnesota, 500 Pillsbury Drive SE, Minneapolis, \\ MN 55455, USA; e-mail: dlevinson@umn.edu, huang284@umn.edu \\ Received 14 July 2010; in revised form 13 January 2011
}

\begin{abstract}
In this paper we develop a positive theory of network connectivity, seeking to provide the microfoundations of alternative network topologies as the result of self-interested actors. By building roads, landowners hope to increase their parcels' accessibility and economic value. A simulation model is performed on a grid-like land-use layer with a downtown in the center. The degree to which the networks are tree-like is evaluated. This research posits that road networks experience an evolutionary process where a tree-like structure first emerges around the centered parcel before the network pushes outward to the periphery. Road network topology becomes increasingly connected as the accessibility value of reaching other parcels increases. The results demonstrate that, even without a centralized authority, road networks can display the property of self-organization and evolution, and that, in the absence of intervention, the degree to which a network structure is tree-like or web-like results from the underlying economies.
\end{abstract}

Keywords: road network, network growth, network structure, treeness, circuitness, topology

\section{Introduction}

The design of street patterns in cities is contentious. Traditional engineering design guidelines argue for a hierarchical, even tree-like, street and highway pattern (AASHTO, 2001), particularly in new suburban environments. Many urban designers propose a flatter, web-like pattern developing organically (Alexander, 1965) or from plans (Grammenos et al, 2008; Martin, 2008). Aspects of network form have been codified in design principles both historically (Ben-Joseph, 2005; Ben-Joseph and Szold, 2005; Southworth and Ben-Joseph, 2003) and for transit-oriented development (Jacobson and Forsyth, 2008). This debate has been held at a normative level, with arguments about which pattern satisfies different values and purposes (eg, efficiency for cars versus efficiency for pedestrians, how to deal with through traffic, and what is the best allocation of land between transportation and other uses). Such different values and purposes are reflected not only in existing street patterns, but also in the process of constructing these networks.

Road networks may be specified using top-down or bottom-up mechanisms. The top-down mechanism assumes that road networks are planned by an authorized agency, such as governmental or quasi-governmental sectors. The mechanism frequently features centralized objectives (such as maximizing travel speeds on the network, minimizing overall cost, and enhancing accessibility). One example often given is the US Interstate Highway System which was planned and financed by the US federal government under the Federal-Aid Highway Act of 1956 (Rae, 1971). As the world's longest highway system, it has been dubbed as "the greatest public works project in history" (Weingroff, 2006). Though this is largely considered to be a topdown process and the general connectivity between cities was given by the plan, the details of the location of routes, and especially spurs, was iteratively decided between local, metropolitan, state, and the federal governments. 
The other category is a bottom-up mechanism, meaning that roads emerge from a decentralized and spontaneous construction process. The UK turnpike system from the 17 th to the 19th century is an example of decentralized efforts. The turnpike system was not planned centrally but built by local trustees who were authorized to levy tolls on the turnpikes they constructed. The turnpike system included both new and reconstructed roads (Buchanan, 1990), and local residents were responsible for maintaining part of the turnpikes (Albert, 2007). This largely bottom-up approach created a remarkable road system in the UK in the 18th century, although there was still a top-down regulatory mechanism in that turnpike trusts required parliamentary approval.

Modern road systems probably cannot be built and maintained completely by individuals, but collaborations with other individuals (typically in the from of development companies) enables the building of most of the length of the road network (typically requiring government approval and subject to regulation, but following the devleoper's plans and using the developer's capital), and local governments build more road networks than higher levels of government. Many of the more important roads have long histories, and had incipient forms that were the creation of individuals acting along or together. As Powers (1910, page AU5) indicated, "Our public roads are an evolution from the primary paths made by animals and by men. Of the identity of the first beings who made paths in the wilderness we are uncertain. Whatever their character and origin, we may be reasonably certain that they had roads of some sort."

The emergence of the "roads of some sort", without a centralized plan, must involve numerous spontaneous interactions. From individuals' spontaneous interactions in a community, the order of road networks can evolve (Ben-Joseph, 2005), that is, road networks can self-organize. What properties do these networks display? What theory underlies the mechanism?

On the basis of a microeconomic model of road network growth, we develop here a positive theory of network connectivity for road networks in a decentralized context. The intent is to illustrate the feasibility of self-organization to provide insights into the dynamics of road network growth (ie, capture the evolution of the system rather than just its end state), and to suggest implications for planning practice. This is a critical point in that the door of alternative regulations and planning may be opened after the principles of the "invisible hand" of the market are understood.

This research models the impact of individual parcel owners' behavior on road network patterns. The model is based on the innovations of individual agents, the developers and the residential and commercial locators they serve, rather than a normative theory based on the ideals of planners, architects, or engineers. The idea accords with Powers's (1910) review of the history of road building in the US. First, the early roads were built due to a cell for communication and navigation. In this research, we assume that roads are constructed by self-interested parcel owners who aim to increase the value of their own land parcels measured by accessibility. Second, "road buildings began at centers and spread out with the spread of population" (Powers, 1910, page AU5). In this paper a center with the highest economic value of accessibility is presumed to exist and therefore other parcel owners want to connect to it. This represents, for instance, the location of a port or railroad station that allows access to the outside world, or it might represent some natural resource, such as a mine. Third, as anecdotal evidence about early roads in Massachusetts Bay Colony depicts, "in 1636 a measure was passed in the Massachusetts Bay Colony which provided that two or three men from adjacent towns get together and lay out proper roads ... provided they did not necessitate pulling down a man's house or going through his garden or orchard" (Powers, 1910, page AU5). 
This paper is organized as follows. The next section reviews the literature on transport network topology and modeling road networks. The third section describes land-use affinity, the attractiveness between key activities that shapes how networks will be constructed. This is followed by a discussion of network configuration and accessibility, which describes alternative street configurations. A simple model of whether a link would be constructed by a self-interested developer is presented, and later this is applied in a simulation to illustrate the different types of connections that might emerge under different circumstances. We conclude with a discussion and policy implications.

\section{Literature}

Since Euler (1736) first studied the seven bridges problem in Königsberg, transport networks have been a topic of extensive study. A network can be represented graphically by a set of nodes and a set of edges connecting these nodes. In the transport context, locations or places can be seen as nodes, and edges are the physical constructs, such as the highway, aviation, or railway network. Different transport networks have been found to display interesting patterns. For example, the US airline networks feature the hub-and-spoke structure (Shaw, 1993). The worldwide air transport network is a scale-free, small-world network (Guimera et al, 2005). The railway network in India displays small-world properties ${ }^{(1)}$ (Sen et al, 2003), and the US road network consists of a hierarchy of roads (such as local streets, linking collectors, arterials, and freeways) (Levinson, 2005). A comprehensive review of network structures and measures can be found in Boccaletti et al (2006).

Different transport network topologies emerge out of different contexts and backgrounds. For instance, to a large extent the hub-and-spoke airline network structure is shaped by the airline industry deregulation policies, under which for-profit airlines seek to minimize cost and provide better services for large markets (Goetz and Sutton, 1997), coupled with underlying economic structures due to the technology. In comparison, the hierarchy of roads is designed to achieve an efficient road system given different objectives of travel and interactions between roadway use and land use (Rosenthal and Strange, 2001). Yerra and Levinson (2005) contend that the hierarchy of a road emerges even without a centralized designer. Their model replicates different speed levels for the road system using decentralized revenue and investment rules. It implies that very different mechanisms can produce similar road patterns.

A variety of studies have modeled the growth or road networks based on different mechanisms, which can be cataloged into three streams. First, in probabilistic network growth models each link is presumably born with a probability. There have been many attempts to describe urban form, developing mathematical models of connectivity (Salingaros, 1998; 2000; Salingaros et al, 2005) and urban growth (Batty, 2006; Batty and Longley, 1986; Longley et al, 1991). A notable example is the random graph model, arguably the first application of modern graph theory to explain real-world networks (Erdös and Rényi, 1959). Other approaches include the exponential model (Dorogovtsev and Mendes, 2002), the preferential attachment model (Barabási and Albert, 1999; Price, 1965), the Markov graph (Frank and Strauss, 1986; Wasserman and Pattison, 1996), and the Newman-Gastner model (Gastner and Newman, 2006).

(1) The small-world property is that although not adjacent to each other, most nodes can be reached from every other by a small number of hops or steps. 
Second, in network design models a link is built to optimize a centralized objective, such as minimizing the Euclidean distance (Gastner and Newman, 2006), minimizing detour (Schweitzer et al, 1998), or maximizing transport potential between two locations (Yamins et al, 2003).

Third, in agent-based models agents construct links with local objectives. For example, Helbing et al $(1997 ; 1998)$ adopt an active walker model to reproduce the evolution of trains in urban green spaces. Yerra and Levinson (2005) model network growth with localized investment rules. Levinson and Yerra (2006) investigate the selforganization of road networks using a travel demand model coupled with revenue, cost, and investment models. Xie and Levinson (2009a) adopt an iterative process of network loading, traffic demand dynamics, investment, and disinvestment. Such decentralized agent-based approaches provide a bottom-up perspective to examine phase changes of network growth, path dependency (Arthur, 1989), and multiple equilibria (Correa et al, 2004; Yang, 1998). Models of road network growth have been reviewed in Xie and Levinson (2000b).

Modeling road networks is frequently related with land-use issues because individuals travel on roads to access desired activities and services. The next two sections will elaborate on the spatial relationship between land use and network configurations through the concept of accessibility.

\section{Land-use affinity}

Land use and transport have been seen as closely related. Dating back to the 19th century, von Thünen (1826) identified the relationship between land rent, yield of land, market price of product, and transport cost. Christaller (1933) proposed a hierarchy of communities in terms of a variety of stores; goods of higher order tend to stay farther away from each other than goods of lower order in that they serve a larger threshold population. Lösch (1940) argued that the distribution of manufacturing production can self-organize into honeycombs of regular hexagons in order to balance between competition and occupying the market.

To understand the relationship between activity types, in this research we assume there are two major types of places: homes and firms. People (who in this simple model are all workers) live in homes and are employed at workplaces (firms).

Firms want to be near other firms because economies of agglomeration emerge when different firms colocate. These economies lower costs of production (or increase quality). Agglomeration economies, sometimes referred to as external economies of scale, extend traditional internal, or firm-level, economies of scale, which as a firm increases production reduces its per unit average cost (Rosenthal and Strange, 2004). Sources of agglomeration economies include:

- labor-market pooling and other input sharing (sharing),

- access to specialized goods and services (matching),

- technological spillovers (learning),

- natural advantage,

- home-market effects,

- consumption opportunities, and

- rent seeking.

Marshall (1920) developed and Duranton and Puga (2004) further described the first three points. Natural advantage has to do with some inherent ability to have lower production costs in a particular location, due, for example, to the presence of an input (eg, milling companies locating near waterfalls before electric transmission networks). Home-market effects exist when local demand for a good (such as snowmobiles in northern Minnesota) exceeds the average demand. Economies of consumption have 
several sources, and the ability to comparison shop for both substitutes and complements may make a district advantageous to consumers (who can economize on travel costs by trip chaining) and create demand for stores to be near competitors (since consumers may be more likely to shop at a store in a cluster than one away from either competitors or complements) (Huang and Levinson, 2009; 2011). Further, the joint location of complementary firms means that the 'complement of my complement' will also be colocated, which may be a direct competitor. When firms do desire to colocate, this must outweigh any negative effects of being near other employers, such as having to pay more for labor.

Firms want to be near workers, because workers constitute a major input to the production process. Also, having a nearby workforce means that firms can pay less to those workers as travel costs need not be compensated. Workers want to be near firms which provide jobs since being near more jobs means there is additional demand and thus higher wages. However, workers also want to live in homes far from other workers, since this reduces both competition for jobs (and thus means higher wages) and competition for land (and thus means lower rents and more space). This last 'centrifugal' factor keeps cities from converging onto a single point. Table 1 summarizes these relationships.

Table 1. Affinity between types of places. Plus $(+)$ indicates attraction, minus $(-)$ indicates aversion.

\section{Firms Homes}

Firms ++

Homes $\quad+$

An analysis of residential prices as a function of accessibility to jobs and to workers (El-Geneidy and Levinson, 2006) corroborates the observation that workers want proximity to jobs and separation from other workers. The affinity of workers for jobs applies to subcenters as well as central business districts (Cho et al, 2008). Similarly, firms who provided jobs seem to have an affinity for potential labor (Scott and Horner, 2008). This logic bears some resemblance to Krugman (1996), though that model fixed workers rather than modeling their dynamics, and underlies Levinson et al (2007), who modeled locational dynamics and network speed and capacity, but kept network topology fixed.

\section{Network configurations and accessibility}

In this study we model the road network as an undirected graph on a land-use layer comprising a grid of land parcels which roads cannot cross. While the grid-like pattern is idealized, it has been widely adopted in many places in the US ${ }^{(2)}$ and elsewhere (Ben-Joseph, 2005; Marcuse, 1987; Stanislawski, 1946). To illustrate, the two downtowns in the Minneapolis - St Paul Metropolitan Area have a typical grid-like pattern (see the 1906 map in figure 1). Given the historical accounts, we endeavor to match our model to the real environment yet also to make it simple enough to convey the results and implications most clearly. We measure and assess the topological properties of road networks from our model and the dynamic process which generates them.

US cities typically possess a highly integrated network of streets in central business districts and to a lesser, but still significant, extent in older residential areas. However in newer, post-World-War-II residential areas, networks have a lower level of connectivity.

(2) The wide adoption of the grid-like pattern mainly results from the history of land-survey practice in the US in the 18th century, although whether its benefit outweighs its cost remains in question. 


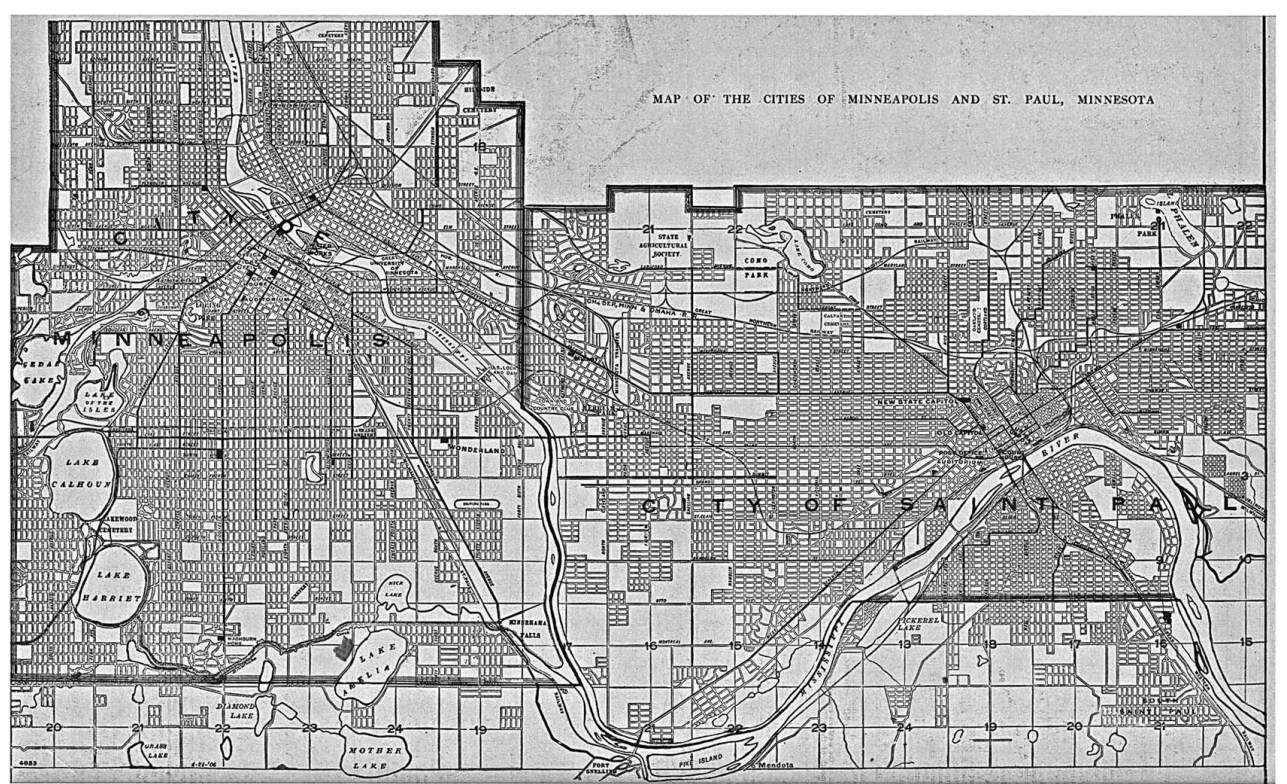

Figure 1. Road map of Minneapolis - St Paul, MN, 1906 (The New Encyclopedic Atlas and Gazetteer of the World edited and revised by F J Reynolds, 1917) (source: http://www.lib.utexas.edu/maps/ historical/minneapolis_1906.jpg).

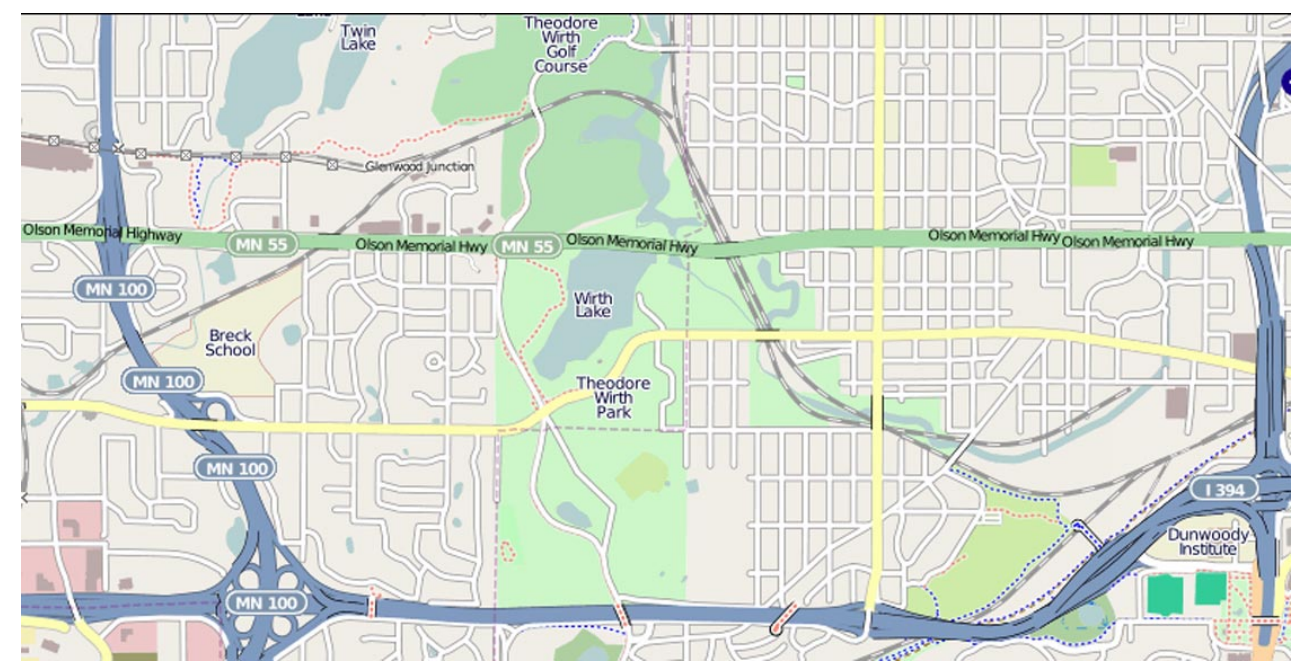

Figure 2. [In color online, see http://dx.doi.org/10.1068/b37094] Golden Valley and North Minneapolis. Golden Valley is to the west of Theodore Wirth Park; Minneapolis is to the east (source: http:// OpenStreetMap.org).

This is illustrated in figure 2 by comparing Golden Valley, a largely post-World-War-II, first ring suburb of Minneapolis on the west of Theodore Wirth Park (and north of I-394), with a largely residential area of North Minneapolis, which is to the east of the park. Downtown Minneapolis is at the very eastern edge of the figure. Minneapolis is grid like and highly connected. Golden Valley has a much lower share of through streets, more cul-de-sacs, and larger block sizes (and thus fewer $\mathrm{km}$ of roads per $\mathrm{km}^{2}$ of area). In the most southwest corner of figure 2 there is an office park and retail center at the interchange of I-394 and Mn 100. 
On the basis of these and similar observations, transport geography defines two basic types of network configurations, trees and circuits. A tree-like configuration is strictly hierarchical: to go to any point from a point, one can proceed down a path toward the center. There is only one path between an origin and a destination. If your destination is on the same branch as the origin, you can reach your destination directly, but if it is on a different branch, you must go into the first common point on the network between the various points and the center, and then proceed outward. In contrast, a web-like configuration presents multiple paths between origins and destinations.

Many-to-one and one-to-many networks are often well served by tree-like structures; examples include water and sewer networks, broadcasting transmission systems, and natural gas pipelines. Communication and transport networks, which need to support many-to-many transactions, may not be able to scale efficiently using treelike structures, and thus often develop more cross-connections. There are reasons for even one-to-many type networks having multiple paths, including variable demands requiring distributed capacity, and network reliability (eg, on an electric grid, or a wire goes down, will electricity still flow?). There are also examples of efficient transport networks (eg, freight logistics, FedEx being the most illustrative) where all shipments are sent to a single national center (eg, Memphis) for sorting before being redistributed even if the shipment is local.

Both transport networks and places are organized hierarchically. Road networks have local streets at the base of the hierarchy, serving primarily to enable land access at low speeds and low levels of traffic, and interstate highways at the top, serving high volumes of fast, longer distance movements, as shown in figure 3. Places range from individual buildings (eg, a condominium association) through neighborhoods, towns or cities, counties, states, and countries.
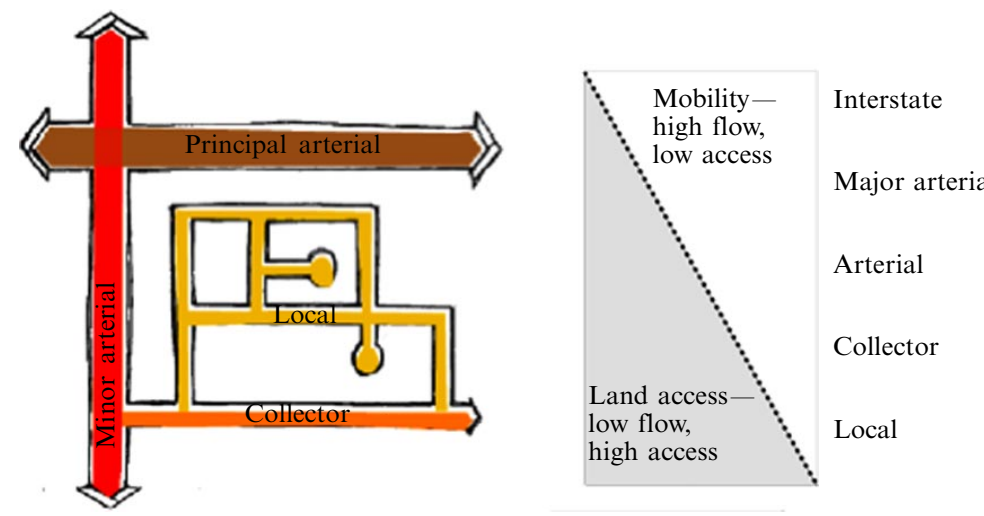

Figure 3. [In color online.] Hierarchy of roads (source: Levinson and Krizek, 2008).

There are advantages to a hierarchy of streets in that it: aggregates traffic so there can be economies of scale in construction and operation; separates access and movement functions to reduce conflict, making both safer; keeps residential neighborhoods quiet; reduces network redundancy; allows exclusion of higher levels; and enables financing by different agencies or levels of government (Levinson and Krizek, 2008). That, however, does not imply there is a necessary advantage to a particular network topology. In the demerits column, a hierarchy: increases travel distance (backtrack costs); increases criticality of specific points (less redundancy means greater vulnerability); creates potential correspondence problems (mismatches) between the level of 
government and the level of road network for which it is responsible; and may be less legible (Lynch, 1960) and thus it increases difficulty in navigation compared with flat networks.

How these hierarchies are organized is related to, but not identical to, the topology. Some topological structures (eg, trees) map directly to hierarchies, which others (eg, circuits) may be hierarchical in function (eg, with some links operating with faster traffic or carrying more flow than others), but the hierarchy is not obvious from a simple graph representation. These topological configurations are defined in Xie and Levinson (2007) and used below.

The advantage of a tree is the lower construction cost (it has a shorter center-line length of network). Its disadvantage is the higher travel distance compared with a web, on which it is easier to travel from and to noncentral locations (less backtracking is required). A web thus has higher accessibility due to its high connectivity. It also has greater redundancy in the case of a failure, while a closed link on a tree will eliminate all access to particular points on the network (Jenelius, 2010). Real street networks are combinations of trees and webs, some are more tree-like, others more web-like.

Accessibility measures the ease of reaching destinations. The higher the travel cost, the lower the accessibility. It also measures the value of destinations: the more activities there are at the destination, the more valuable it is. A variety of measures have been suggested that track accessibility from different perspectives (Geurs and van Wee, 2004; Handy and Niemeier, 1997; Kwan, 1998; Miller, 1991; 1999; Ottensmann and Lindsey, 2008; Weber and Kwan, 2002).

An accessibility increase does two things. First it increases total wealth. Agglomeration economies caused by new infrastructure enlarge aggregate output. Second, it redistributes wealth, as the locations where the accessibility gains are larger gain more of the aggregate wealth. Places which do not increase accessibility by at least the average amount may find themselves losing economic opportunities, since these opportunities will relocate to take advantage of the accessibility benefits.

The next section illustrates the economic theory of network connectivity by introducing a simple agent model. The model considers the contribution of accessibility to road network growth without assuming a central planner.

\section{Economics}

The economic theory of network connectivity that we trace out is one of individual parcel owners behaving in a self-interested way building links in order to maximize profit, with the result that under different circumstances, different network topologies emerge. The variables used in this model are explained in table 2. We can formulate an individual's objective as below.

The marginal profit for parcel owner $i$ (which also indicates parcel $i$ ) to build road $k$ in road set $R$ [indicated by $\Delta \prod_{i}(k)$ ] equals the extra value with road $k$ compared with the value without road $k$ minus the construction expenditures of road $k$.

$$
\Delta \prod_{i}(k)=A_{i}(R[1, \ldots, k])-A_{i}(R[1, \ldots, k-1])-e l_{k},
$$

where

$$
\begin{aligned}
& A_{i}(R)=\sum_{j=1}^{N} w_{j} c_{i j}^{-\delta}, \\
& w_{j}= \begin{cases}w_{\mathrm{c}}, & \text { if } j \text { is the central parcel, } \\
w_{\mathrm{n}}, & \text { otherwise. }\end{cases}
\end{aligned}
$$


Table 2. Descriptions of variables. Some values are fixed.

\begin{tabular}{llr}
\hline Variables & Description & Fixed value \\
\hline$w_{\mathrm{n}}$ & value of land-use accessibility for a noncentral parcel $(\$)$ & 1500 \\
$w_{\mathrm{c}}$ & value of land-use accessibility for the central parcel $(\$)$ & 400 \\
$e$ & road construction cost per unit length $(\$)$ & 500 \\
$\delta$ & distance decay parameter & 0.3 \\
$l_{k}$ & length of road $k$ & 81 \\
$N$ & total number of parcels & \\
$i$ & parcel (owner) ID & \\
$k$ & road ID & \\
$R[1, \ldots, k]$ & road network set consisting of roads from 1 to $k$ & \\
$A_{i}(R)$ & value of land-use accessibility for parcel owner $i$ given road & \\
$\Delta \prod_{i}(k)$ & network $R$ & \\
$w_{j}$ & benefit of land-use accessibility for parcel owner $i$ after & \\
$c_{i j}$ & road $k$ is built \\
\hline
\end{tabular}

Equation (1) calculates the additional benefit of land-use accessibility for parcel owner $i$ after a new on-site road has been built, considering the cost of building this road. The value of accessibility is measured by a gravity model in equation (2) which shows that longer travel distance decreases the value of accessibility. The gravity form is arguably the most widely used accessibility measure and has a strong theoretical and empirical basis (Fotheringham and O'Kelly, 1989; Hansen, 1959; Koenig, 1980; Wilson, 1971). The value of accessibility depends on location and accessibility may be comprised of multiple land-use types. In this research we define two types of land use: central parcel (for commercial use) and noncentral parcel (for residential use). The value of accessing the central parcel equals $w_{\mathrm{c}}$, which is much higher than the value for the noncentral parcel $w_{\mathrm{n}}$.

For parcel owner $i$, if $\Delta \prod_{i}(k)>0$, that is, the benefit of building road $k$ is greater than zero, the on-site road will be constructed. There may even be cases where off-site links would be valuable, but these are much more complicated cases as they require the permission of other parties. However, since they are off-site, they may be of value to other parties as well.

\section{Network topology measures}

Planar transport networks have two basic forms: branching networks and circuit networks (Haggett and Chorley, 1969). Circuit networks have closed circuits, whereas branching networks display tree-like structures. Additionally, Xie and Levinson (2007) formally define structural elements such as branch, ring, circuit, and beltway, and develop an algorithm to measure the degree to which a network is tree-like (or circuit-like). The treeness ratio $\left(\phi_{\text {tree }}\right)$ ranges from 0 to 1 [refer to Xie and Levinson (2007) for details about how to find trees, rings, and webs in a network]. A high treeness ratio means a network is more tree-like. This measure is used to examine the topological connectivity of road networks given different parameter values. 


\section{Simulation model}

\subsection{Assumptions}

In this research we define a road as a physical connection between two adjacent parcels. The road network to be built overlays a grid-like land layer of $N$ land parcels, respectively owned by $N$ parcel owners. The value of a land parcel is determined by its accessibility to other land parcels. Parcel owners build roads to increase the accessibility of their own parcels (and thus increase their parcel values). Roads can only run parallel to the $x$-axis or $y$-axis, with no overpasses. In addition, road construction is irreversible: once a road is built, it cannot be severed. Multiple iterations are run until a stable road pattern emerges (ie, no more new links are built).

The agent model is programmed on the Netlogo platform (see Wilensky, 1999). In programming, we adopt a square-like region as the basic layer with $N$ land parcels. In our outputs, a noncommercial parcel is symbolized with a green circle, and a commercial parcel with a red circle.

Parcel owners take turns to build roads; the sequence is randomly decided. Each parcel owner can choose to build one link between two adjacent land parcels which are not yet connected, or not to build a link. This is a locally selfish, myopic optimization, maximizing short-term benefit for the agent itself, similar to the greedy algorithm.

\subsection{Results and analysis}

The base case is performed in the context of a $9 \times 9$ evenly spaced grid in the form of a square, each point of which stands for a parcel which is owned individually. Fifty iterations are tested in the base case. The parameter values used in the basic simulation are shown in table 2. Initially there is no road. The road network reaches equilibrium at the end of the fourth iteration (ie, no new link is built). Our results find multiple stable road network patterns given different sequences of decision making for parcel owners. Some exemplary patterns are illustrated in figure 4. All the networks consist of tree-like and circuit-like structures. The networks display star-like shapes with a few redundant links among certain branches. On the periphery, the link connectivity is

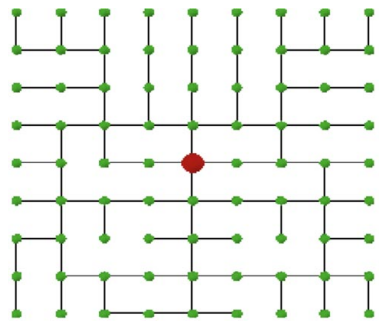

(a)

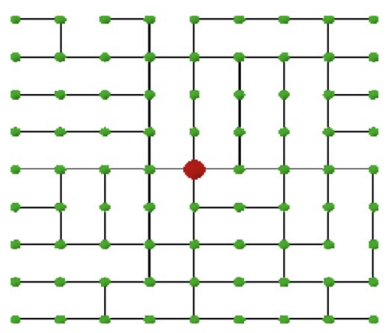

(c)

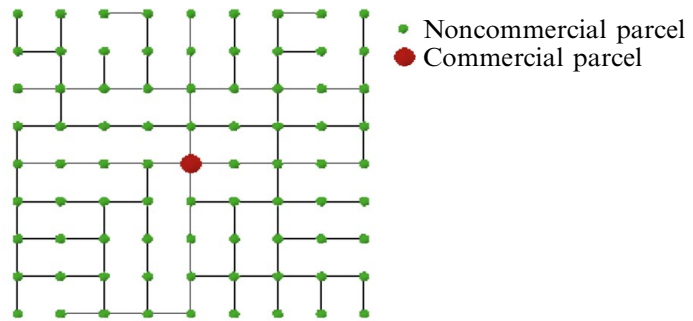

(b)

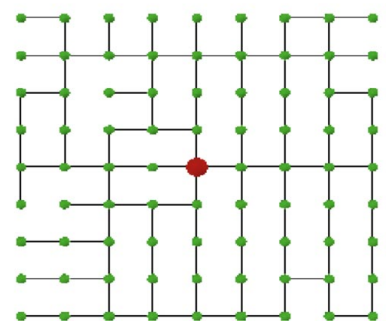

(d)

Figure 4. [In color online.] Exemplary resultant road network patterns given different sequences of decision making for parcel owners, with $\delta=0.3, e=500, w_{\mathrm{n}}=400, w_{\mathrm{c}}=1500, N=81$, and $d=4$. 
similar to a cul-de-sac pattern. Different sequences of decision making for parcel owners lead to different network topologies in both temporal and spatial terms, exhibiting path dependency (Arthur, 1988). Since the center has the highest value of access, the parcels closer to the central parcel connect to the center first.

As more parcels connect to the road network, the value of connecting to the whole network increases, and ultimately all parcels are connected to the network. Figure 5 displays network patterns in each iteration until equilibrium for a particular run of the model. We can see that at the end of the second iteration, the network pattern is still tree-like. At the end of the fourth iteration, the network expands to parcels on the periphery. Redundant links are later added to the tree-like structure. After four iterations the network stops changing, reaching stability. This evolutionary path reveals that road network growth is a dynamic process where new roads are first built to connect to important parcels before they expand to less important parcels. The tree-like structure emerges first; redundant links are later built, rendering multiple traveling paths from one parcel to another.

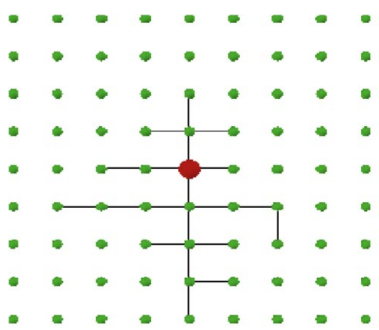

(a)

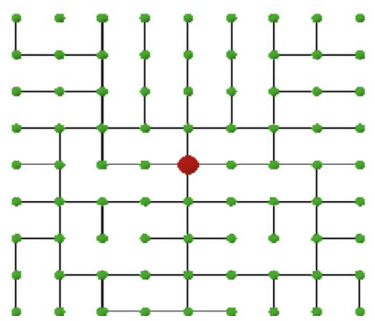

(c)

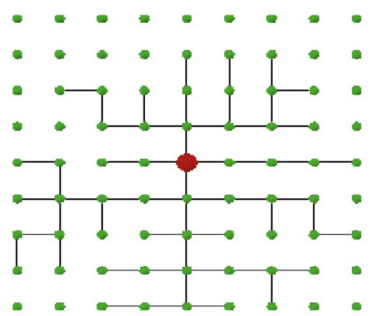

(b)

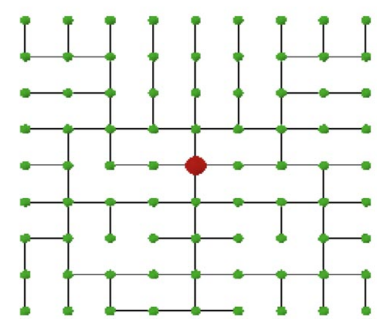

(d)

Figure 5. [In color online.] The evolution of road networks from (a) iteration 1 to (d) iteration 4 (the network structure), with $\delta=0.3, e=500, w_{\mathrm{n}}=400, w_{\mathrm{c}}=1500, N=81$, and $d=4$. There is no road in the beginning. A tree-like structure emerges at the end of the first iteration (a). At the end of iteration 4 (d), the network is fully connected.

What then are the impacts of different values of the key parameters on road network patterns? First we perform a sensitivity test by changing the value of noncentral parcels $w_{\mathrm{n}}$ from 0 to 1000 (with step size 50), while keeping other parameters fixed. Our hypothesis is that as $w_{\mathrm{n}}$ becomes larger, the network contains more links and nodes have better connectivity. As expected, the simulation reveals phase changes (from tree-like to circuit-like structure) for road networks given different values of $w_{n}$. In figure 6, when $w_{\mathrm{n}}$ is lowest, treeness equals 1 (and circuitness equals 0). As $w_{\mathrm{n}}$ increases, treeness generally descends, suggesting a topological evolution from tree-like to circuit-like. 


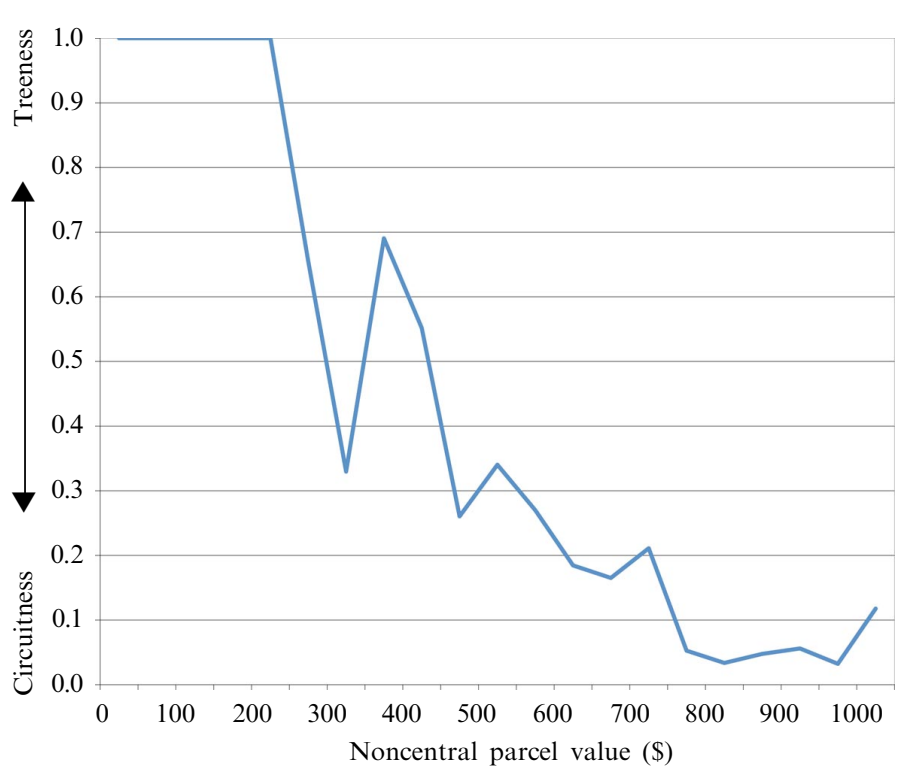

Figure 6. [In color online.] The treeness ratio changes as $w_{\mathrm{n}}$ changes from 0 to 1000 , with $\beta=-0.3, c=500, w_{\mathrm{c}}=1500, N=81$, and $d=4$. When the value of $w_{\mathrm{n}}$ is low, the network is more tree-like; when $w_{\mathrm{n}}$ grows, the network becomes more circuit-like as more redundant or parallel links are constructed.

The second sensitivity text focuses on parameter $e$ (construction cost per unit length of a new road). As its value changes from 0 to 1000, the network evolves from fully connected grid like to less connected circuit-like, and finally reduces to a binary tree. Figure 7 reflects this phenomenon as the treeness ratio diminishes. When $e$ is low, more redundant or parallel links are built. When $e$ is high, only the links around the center are built and the network is completely tree-like. Once $e>900$, there are no links in the network. This shows that construction cost is also an important factor in influencing network structure.

The absolute values of these thresholds depend deeply on modeling assumptions. The existence of thresholds which result in the differentiation between partially connected and fully connected, and between tree-like and web-like networks, however, is an important insight. As values of accessibility change (places become more or less highly valued) or the cost structure changes, market-built networks will take on different topologies.

To understand the road network growth under different geographical patterns, we examine two scenarios, each with nine centers. In the first, these centers are concentrated, in the second they are dispersed. In the case of nine concentrated centers of activity (see figure 8), the central area can be seen as a big cluster of fully connected activity nodes acting as the hub of the network; the grid-like structure is similar to the layout of downtown. Displaying a tree-like structure, other nodes are connected on the spokes of these central nodes, resembling cul-de-sacs in a suburb. The results reveal that areas with high accessibility (such as downtown) tend to be fully connected on the grid network, whereas areas with low accessibility (such as suburban neighbourhoods where residents desire more personal space) will naturally generate tree-like road structures.

We further concentrate on the scenario of nine dispersed centers (see figure 9). Compared with figure 8 , road density tends to be more evenly distributed. The roads around the nine centers are fully connected, and each center is a local hub. The density of road networks in the region first rises and then decreases as the distance from the center increases. 


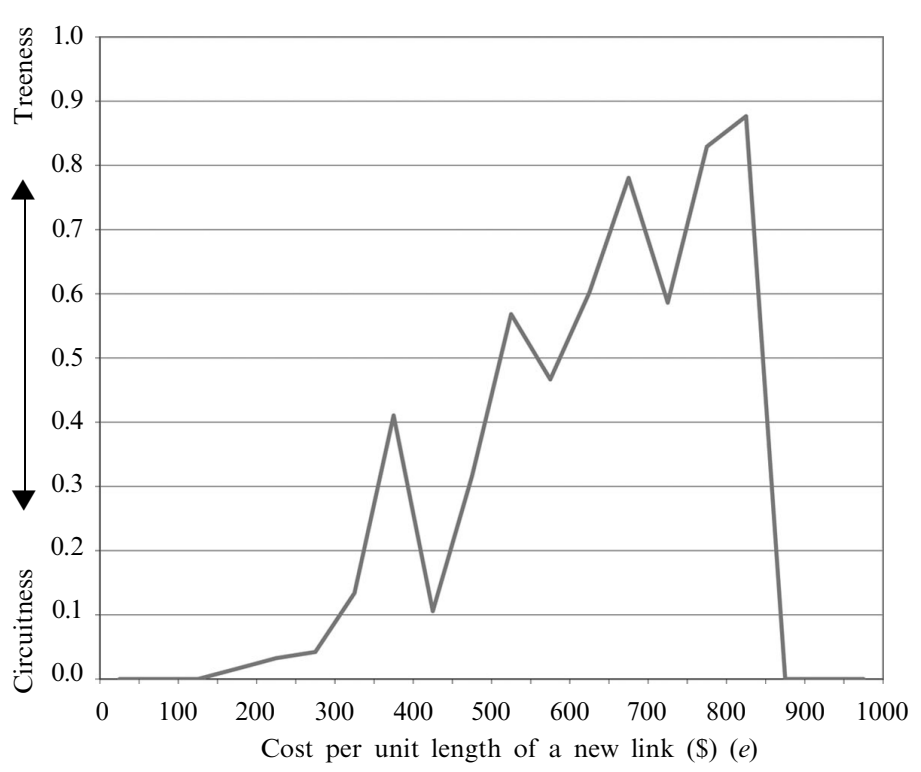

Figure 7. The treeness ratio changes as the cost of construction $e$ changes from 50 to 1000 . When the value of $e$ is low, the network is fully connected. As the cost increases, the network is less connected with a mix of tree-like and circuit-like structures. As the cost increases, the network shrinks to tree-like, when $e>900$, no links are built and treeness is undefined.

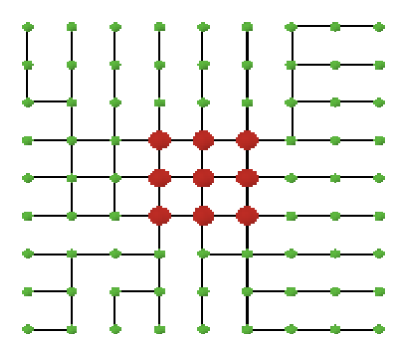

Figure 8. [In color online.] Road network structure in equilibrium in the scenario of nine concentrated activity nodes. The network has both tree-like and circuit-like structures. The network density is the highest for the cluster (marked by red dots); it decreases as one moves farther away from the center.

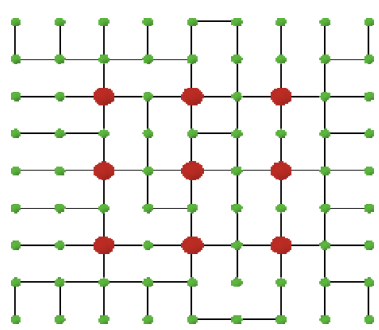

Figure 9. [In color online.] Road network structure in equilibrium in the scenario of nine dispersed single-point centers. The centers all have full connections. On the periphery and between centers there are more tree-like structures.

\section{Discussion and conclusions}

In this paper we propose a positive theory of network connectivity to explain road network growth from a decentralized perspective. In this theory, road networks grow from a nonredundant structure to a redundant one. An agent model is developed to illustrate the dynamics of road network growth. The model is based on the assumption that self-interested land-parcel owners build roads to increase the accessibility of each owner's parcel and thereby to enhance the parcel's value. After reviewing the development of early roads in Minneapolis - St Paul since the late 19th century, we simulate network growth on a grid-like land-use layer with a downtown (the central parcel with high value of accessibility) in the center. First we find that networks evolve from a simple tree-like structure to a web-like structure, which provides multiple paths from 
one destination to another. This finding comports with the growth of the UK turnpike system from a tree-like structure (with London as the center) to a structure with redundant roads, ${ }^{(3)}$ as well as other transportation systems for which historical data are available, such as the Twin Cities (Minneapolis and St Paul) streetcar network.

Our simulation results confirm that the development of road networks can be modeled as an evolutionary process, and that when the economic or social conditions of places reach certain thresholds road network patterns could go through significant phase changes.

This research on topology (with undifferentiated links) provides insights into the formation of early roads, the foundation of today's hierarchical transport systems, and complements research on hierarchical links (varying in speed and capacity) given fixed web-like topology by Yerra and Levinson (2005). While fully recognizing that central authorities have played an important role in advancing current road networks (though often responding to underlying economic pressures), we study the dynamics of roads arising from the spontaneous behaviour of individuals.

Today large US cities have road networks whose per capita capacity is independent of spatial extent. "Road networks are built as though traffic is completely decentralized" (Samaniego and Moses, 2008, page 33), but have flows which reflect a mix of centralized and decentralized land use. This suggests that networks are leading land use in the move towards decentralization, supporting previous findings on transit systems (Levinson, 2008; Xie and Levinson, 2010). That argument is also supported by evidence from Switzerland since 1950, where network investment changed the distribution of population and employment, effectively shrinking the country (Axhausen, 2008).

Although the growth of road networks in the real world is affected by numerous factors, this research sheds light on the effect of a possible economic incentive-the value of accessibility. Our simulation results replicate the dynamic growth of road networks and their phase changes in different economic conditions. Two major implications can be derived.

First, road networks have the property of self-organization and evolution. Even without a central authority or following an optimal design, interesting road network patterns emerge out of the road-building behavior of individual parcel owners. When certain economic conditions are met, roads are built first around the central parcel, and then gradually cover the parcels on the periphery. The tree-like (nonredundant) structure is the emergent topological characteristic in the first stage; as time progresses, the network not only reaches other parcels farther from the center, but also provides multiple paths for parcels that are already connected. Meanwhile the value of the whole network increases for each parcel.

Second, the growth of road networks also features path dependency and phase changes. Regarding path dependency, we find different sequences of decisions lead to different network topologies; moreover, the degrees of connectivity differ for individual but otherwise similar parcels. For phase changes, as the values of some parameters in the model exceed a threshold, road network topology experiences a clear-cut transformation. This implies that even a small variation in certain local economic conditions may trigger fundamental changes for road networks in the long run.

The model assumes selfish actors. Introducing a welfare, rather than a profitmaximizing objective is likely to change the trade-off points, perhaps leading sooner to a more web-like network, but not likely to change the underlying analysis. While regulation may have become more strict in the late 20th century, developments also

(3) A movie on the evolution of the UK turnpikes from the 1720 s to the 1800 s can be found at http://nexus.umn.edu/Movies-Full/UKTurnpike.mov 
became larger on average, so that on-site activities, which remained in the purview of the original developer or parcel owner, became a larger share of the network. This may help to explain the more tree-like, hierarchical aspects of late-20th-century development compared with earlier decades and centuries.

We observe that networks are likely to be dense in the center and become sparser over space as (1) commercial activities transition to residential activities because of economies of agglomeration and relative affinities between land uses, and (2) landuse densities diminish. A natural consequence is that residential areas where the shortened travel time does not outweigh the additional cost of construction will require another mechanism in order to obtain through links. Some mechanisms are outlined below:

- public provision of local roads,

- rules embedded in subdivision ordinances,

- large developments that can internalize the otherwise external benefit of throughconnectivity, or

- side payments from other developers in order to obtain through links.

In the absence of such a mechanism, the local street network will retain the lollipop-like cul-de-sac pattern found in modern suburbs. Our results imply that one possible reason for lower road density and connectivity in suburbs is that the value of connecting places in suburbs is lower than in central places (and/or perhaps the cost is higher), and therefore fewer roads are built in a completely decentralized scenario. Yet, given the existence of regulatory forces, a place of the lowest value of accessibility does not have to wait until the last to be connected. A governing body can allocate resources to build roads for these places as needed, or change the value of accessibility in the place by policy (eg, through zoning or tax incentives).

While the model is based on a very simplified scenario, it provides insights into the dynamics and economics of the growth of road networks in a decentralized mechanism. The reason we chose to keep the decentralized feature is that in this study we aimed to unveil the evolution of road networks without interference from a governing body, wherein identification of causal relationships and principles would be more clear-cut.

Future work to expand this model can take four directions. First, the value of accessibility per parcel $\left(w_{\mathrm{c}}\right.$ and $\left.w_{\mathrm{n}}\right)$ is fixed in the model. In the future we can adjust the value over time with the change of road network topology, so that we can quantitatively examine how this relationship impacts the evolution of road networks. Second, while the affinity theory in table 1 shows four spatial relationships for commercial and residential uses, our simulation models cover two relationships, respectively, to residential and to commercial uses (without distinguishing how different origins may value the different destinations). Our future work will differentiate the relationships (allowing residential-commercial, residential-residential, commercial-residential, commercial-commercial to all have different values). Third, the model is only tested using a gridiron structure to illustrate the essence of the theory. One extension is to test different patterns such as a hexagon-like structure or hub-and-spoke structure with nonparallel roads. Fourth, it is probably worthwhile to compare our resulting network with a network that is the product of centralized planning (given such an objective as minimizing construction or maximizing network accessibility). Such comparisons may provide insights into the balance of public and private roles in road construction. 


\section{References}

AASHTO, 2001 Policy on Geometric Design of Highways and Streets American Association of State Highway and Transportation Officials, Washington, DC

Albert W, 2007 The Turnpike Road System in England: 1663 - 1840 (Cambridge University Press, Cambridge)

Alexander C, 1965, "A city is not a tree" Architectural Forum $12258-61$

Arthur W B, 1988, "Urban systems and historical path dependence", in Cities and Their Vital Systems: Infrastructure Past, Present, and Future Eds J H Ausubel, R Herman (National Academy Press, Washington, DC) pp 85-97

Arthur W B, 1989, "Competing technologies, increasing returns, and lock-in by historical events" The Economic Journal 99116 - 131

Axhausen K, 2008, "Accessibility: long-term perspectives” Journal of Transport and Land 1(2) $5-22$

Barabási A L, Albert R, 1999, “Emergence of scaling in random networks” Science $\mathbf{2 8 6} 509$

Batty M, 2006, "Hierarchy in cities and city systems", in Hierarchy in Natural and Social Sciences Ed. D Pumain (Springer, Dordrecht) pp $143-168$

Batty M, Longley P, 1986, "The fractal simulation of urban structure" Environment and Planning $A$ $181143-1179$

Ben-Joseph E, 2005 The Code of the City: Standards and the Hidden Language of Place Making (Oxford University Press, New York)

Ben-Joseph E, Szold T, 2005 Regulating Place: Standards and the Shaping of Urban America (Routledge, New York)

Boccaletti S, Latora V, Moreno Y, Chavez M, Hwang D, 2006, "Complex networks: structure and dynamics" Physics Report 424175 -308

Buchanan B, 1990, "Turnpike roads: a classic trap?" Journal of Transport History 36 1425-1464

Cho E, Rodriguez D, Song Y, 2008, "The role of employment subcenters in residential location decisions" Journal of Transport and Land Use 1(2) 121 - 151

Christaller W, 1933 Die zentralen Orte in Süddeutschland (Gustav Fischer, Jena); English translation The Central Places of Southern Germany (1966) (Prentice-Hall, Englewood Cliffs, NJ)

Correa J, Schulz A, Stier-Moses N, 2004, "Selfish routing in capacitated networks" Mathematics of Operations Research 29961 -976

Dorogovtsev S, Mendes J, 2002, "Evolution of networks" Advances in Physics 51 1079-1187

Duranton G, Puga D, 2004, "Micro-foundations of urban agglomeration economies" Handbook of Regional and Urban Economics $42063-2117$

El-Geneidy A, Levinson D, 2006, "Access to destinations: development of accessibility measures", technical report, Minnesota Department of Transportation

Erdös P, Rényi A, 1959, “On random graphs” Publicationes Mathematicae 6290 - 297

Euler L, 1736, "Solutio problematis ad geometriam situs pertinentis" Commentarii Academiae Scientiarum Imperialis Petropolitanae $8128-140$

Fotheringham A, O'Kelly M, 1989 Spatial Interaction Models: Formulations and Applications (Kluwer Academic, Boston, MA)

Frank O, Strauss D, 1986, "Markov graphs" Journal of the American Statistical Association 81 $832-842$

Gastner M, Newman M, 2006, "Shape and efficiency in spatial distribution networks" Journal of Statistical Mechanics 101015

Geurs K T, van Wee B, 2004, "Accessibility evaluation of land-use and transport strategies: review and research directions" Journal of Transport Geography 12 127-140

Goetz A, Sutton C, 1997, "The geography of deregulation in the US airline industry" Annals of the Association of American Geographers 87238 -263

Grammenos F, Craig B, Pollard D, Guerrera C, 2008, "Hippodamus rides to Radburn: a new model for the 21st century" Journal of Urban Design 13163 - 176

Guimera R, Mossa S, Turtschi A, Amaral L, 2005, "The worldwide air transportation network: anomalous centrality, community structure, and cities' global roles" Proceedings of the National Academy of Sciences of the United States of America $1027794-7799$

Haggett P, Chorley R, 1969 Network Analysis in Geography (Edward Arnold, London)

Handy S L, Niemeier D A, 1997, "Measuring accessibility: an exploration of issues and alternatives" Environment and Planning A 291175 - 1194

Hansen W, 1959, "How accessibility shapes land use" Journal of the American Institute of Planners $2573-76$ 
Helbing D, Schweitzer F, Keltsch J, Molnar P, 1997, "Active walker model for the formation of human and animal trail systems" Physical Review E 562527 - 2539

Helbing D, Keltsch J, Molnár P, 1998, "Modelling the evolution of human trail systems" Nature $38847-50$

Huang A, Levinson D, 2009, "Retail location choice with complementary goods: an agent-based model", in Complex Sciences Ed. I Zhow (Springer, Berlin) pp 175- 187

Huang A, Levinson D, 2011, "Why retailers cluster: an agent model of location choice on supply chains" Environment and Planning B: Planning and Design 38 82-94

Jacobson J, Forsyth A, 2008, "Seven American TODs: good practices for urban design in transit-oriented development projects" Journal of Transport and Land Use 1(2) 51 -88

Jenelius E, 2010, "User inequality implications of road network vulnerability" Journal of Transport and Land Use 2(3/4) $57-73$

Koenig J, 1980, "Indicators of urban accessibility: theory and application" Transportation 9145 - 172

Krugman P, 1996 The Self Organizing Economy (Blackwell, Oxford)

Kwan M-P, 1998, "Space - time and integral measures of individual accessibility: a comparative analysis using a point-based framework" Geographical Analysis $30191-216$

Levinson D, 2005, "Paying for the fixed costs of roads" Journal of Transport Economics and Policy $39279-294$

Levinson D, 2008, "Density and dispersion: the co-development of land use and rail in London" Journal of Economic Geography $855-77$

Levinson D, Krizek K, 2008 Planning for Place and Plexus: Metropolitan Land Use and Transport (Routledge, New York)

Levinson D, Yerra B, 2006, "Self-organization of surface transportation networks" Transportation Science $40179-188$

Levinson D, Xie F, Zhu S, 2007, "The co-evolution of land use and road networks", in Seventeenth International Symposium on Transportation and Traffic Theory at Imperial College, London Eds R E Allsop, M G H Bell, B Heydecker (Emerald, Bradford, West Yorkshire) pp 839-859

Longley P, Batty M, Shepherd J, 1991, "The size, shape and dimension of urban settlements" Transactions of the Institute of British Geographers, New Series 1675 -94

Lösch A, 1940 Die räumliche Ordnung der Wirtschaft (Fisher, Jena); English translation The Economies of Location (1954) (Yale University Press, New Haven, CT)

Lynch K, 1960 The Image of the City (MIT Press, Cambridge, MA)

Marcuse P, 1987, "The grid as city plan: New York City and laissez-faire planning in the nineteenth century" Planning Perspectives 287 - 310

Marshall A, 1920 Principles of Economics: An Introductory Volume (Macmillan, London)

Martin L, 2008, "The grid as generator" Architectural Research Quarterly 4 309-322

Miller H J, 1991, "Modelling accessibility using space - time prism concepts within geographic information systems" International Journal of Geographic Information Systems 5287 -301

Miller H J, 1999, "Measuring space - time accessibility benefits within transportation networks: basic theory and computational procedures" Geographical Analysis 31 1-26

Ottensmann J, Lindsey G, 2008, "A use-based measure of accessibility to linear features to predict urban trail use" Journal of Transport and Land Use 1(1) $41-63$

Powers E L, 1910, "History of road building: first law to improve United States highways passed in 1639" The New York Times 2 January

Price D J, 1965, "Networks of scientific papers" Science 149510

Rae J B, 1971 The Road and the Car in American Life (MIT Press, Cambridge, MA)

Rosenthal S S, Strange W C, 2001, "A four level road hierarchy for network planning and management", in Proceedings of the 20th ARRB Conference Melbourne, Ed. V Jaeger, http://www.eprints.qut.edu.au/2349/2349.pdf

Rosenthal S, Strange W, 2004, "Evidence on the nature and sources of agglomeration economies" Handbook of Regional and Urban Economics, Volume 4 (Elsevier, Amsterdam) pp 2119-2171

Salingaros N, 1998, "Theory of the urban web" Journal of Urban Design 3 53-71

Salingaros N, 2000, "Complexity and urban coherence" Journal of Urban Design 5 291 - 316

Salingaros N, Coward L, West B, van Bilsen A, 2005 Principles of Urban Structure (Techne, Delft)

Samaniego H, Moses M, 2008, "Cities as organisms: allometric scaling of urban road networks" Journal of Transport and Land Use 1(1) 21 - 39

Schweitzer F, Ebeling W, Rose H,Weiss O, 1998, “Optimization of road networks using evolutionary strategies" Evolutionary Computation 5 419-438 
Scott D, Horner M, 2008, "Examining the role of urban form in shaping people's accessibility to opportunities: an exploratory spatial data analysis" Journal of Transport and Land Use 1(2) $89-119$

Sen P, Dasgupta S, Chatterjee A, Sreeram P, Mukherjee G, Manna S, 2003, "Small-world properties of the Indian railway network" Physical Review E 6736106

Shaw S, 1993, "Hub structures of major US passenger airlines" Journal of Transport Geography $147-58$

Southworth M, Ben-Joseph E, 2003 Streets and the Shaping of Towns and Cities (Island Press, Washington, DC)

Stanislawski D, 1946, "The origin and spread of the grid-pattern town" Geographical Review 36 $105-120$

von Thünen J H, 1826 Der isolierte Staat in Beziehung auf Landwirtschaft und Nationalökonomie, 1 (Perthes, Hamburg); English translation: Wartenberg C M, 1966 von Thünen's Isolated State (Pergamon Press, Oxford)

Wasserman S, Pattison P, 1996, "Logit models and logistic regressions for social networks: I. An introduction to Markov graphs and p" Psychometrika $61401-425$

Weber J, Kwan M-P, 2002, "Bringing time back in: a study on the influence of travel time variations and facility opening hours on individual accessibility" The Professional Geographer 54 226-240

Weingroff R, 2006, "The year of the Interstate" Public Roads 69 http://www.fhwa.dot.gov/ publications/publicroads/06jan/01.cfm

Wilensky U, 1999, "NetLogo", Center for Connected Learning and Computer-Based Modeling, Northwestern University, Evanston, IL, http://ccl.northwestern.edu/netlogo/

Wilson A, 1971, "A family of spatial interaction models, and associated developments" Environment and Planning $31-32$

Xie F, Levinson D, 2007, "Measuring the structure of road networks" Geographical Analysis 39336

Xie F, Levinson D, 2009a, "The topological evolution of road networks" Computers, Environment, and Urban Systems $33211-223$

Xie F, Levinson D, 2009b, "Modeling the growth of transportation networks: a comprehensive review" Networks and Spatial Economics 9291 - 307

Xie F, Levinson D, 2010, "How streetcars shaped suburbanization: a Granger causality analysis of land use and transit in the Twin Cities" Journal of Economic Geography 10453 - 470

Yamins D, Rasmussen S, Fogel D, 2003, "Growing urban roads" Networks and Spatial Economics $369-85$

Yang H, 1998, "Multiple equilibrium behaviors and advanced traveler information systems with endogenous market penetration" Transportation Research Part B 32 205-218

Yerra B, Levinson D, 2005, "The emergence of hierarchy in transportation networks" The Annals of Regional Science $39541-553$ 
Conditions of use. This article may be downloaded from the E\&P website for personal research by members of subscribing organisations. This PDF may not be placed on any website (or other online distribution system) without permission of the publisher. 